\title{
Effects of Exercise Programs on Anxiety in Individuals with Disabilities: A Systematic Review with a Meta-Analysis
}

\author{
Miguel Jacinto ${ }^{1,2, *}$, Roberta Frontini ${ }^{2,3}\left(\mathbb{D}\right.$, , Rui Matos ${ }^{2,4}(\mathbb{D})$ and Raul Antunes $2,3,4(\mathbb{D}$ \\ 1 Faculty of Sport Sciences and Physical Education, University of Coimbra, 3040-248 Coimbra, Portugal \\ 2 Life Quality Research Centre (CIEQV), 2040-413 Rio Maior, Portugal; roberta_frontini@hotmail.com (R.F.); \\ rui.matos@ipleiria.pt (R.M.); raul.antunes@ipleiria.pt (R.A.) \\ 3 Center for Innovative Care and Health Technology (ciTechCare), Polytechnic Institute of Leiria, \\ 2410-541 Leiria, Portugal \\ 4 School of Education and Social Sciences, Polytechnic Institute of Leiria, 2411-901 Leiria, Portugal \\ * Correspondence: miguel.s.jacinto@ipleiria.pt
}

Citation: Jacinto, M.; Frontini, R. Matos, R.; Antunes, R. Effects of Exercise Programs on Anxiety in Individuals with Disabilities: A Systematic Review with a Meta-Analysis. Healthcare 2021, 9 , 1047. https://doi.org/10.3390/ healthcare 9081047

Academic Editor: Alessandro Sartorio

Received: 14 July 2021

Accepted: 11 August 2021

Published: 13 August 2021

Publisher's Note: MDPI stays neutral with regard to jurisdictional claims in published maps and institutional affiliations.

Copyright: (c) 2021 by the authors. Licensee MDPI, Basel, Switzerland. This article is an open access article distributed under the terms and conditions of the Creative Commons Attribution (CC BY) license (https:// creativecommons.org/licenses/by/ $4.0 /)$.

\begin{abstract}
Anxiety symptoms are increasingly prevalent in individuals and may affect their quality of life. Physical exercise (PE) has been shown to be an effective method for reducing anxiety symptoms in the general population. The present study aimed to identify if PE programs can be a good method to reduce anxiety symptoms in individuals with disabilities, through the methodology of a systematic review with a meta-analysis. The PubMed, Web of Science, Scopus, and SPORTDiscus databases were used, considering the period from 2001 to 2021. The descriptors used were: "cerebral palsy", "motor disability", "physical disability", "vision impairment", "visual impairment", "vision disability", "intellectual disability", "mental retardation", "intellectual disabilities", "hearing impairment", "hearing disability", "multiple disabilities", "physical activity", "exercise", "sport”, "training", and "anxiety", with the Boolean operator "AND" or "OR". The systematic review with a meta-analysis was carried out in the period between May and June 2021. The $Z$ values ( $Z$-values) obtained to test the null hypothesis, according to which the difference between means is zero, demonstrated a $Z=2.957$, and a corresponding $p$-value of 0.003 . Thus, we can reject the null hypothesis, and affirm that PE promotes positive effects and can be a good method or methodology for the reduction of anxiety symptoms of individuals with disabilities.
\end{abstract}

Keywords: anxiety; disabilities; physical exercise program

\section{Introduction}

Anxiety is characterized by the existence of apprehensive expectation or fear in individuals, being one of the most prevalent psychiatric symptoms across the world [1,2]. It affects approximately one out of five individuals [3-5], regardless of gender, race, or age groups [6]. In the International Statistical Classification of Diseases and Related Health Problems created by the World Health Organization, tenth version (ICD-10), anxiety disorders are classified in the group of mental and behavioral disorders, specifically neurotic disorders. In turn, there is a chapter on the Diagnostic and Statistical Manual of Mental Disorders [1] that contains various possible diagnoses, where anxiety disorders are presented and described.

Anxiety symptoms are also prevalent in individuals with intellectual [7], visual [8], hearing [9], and motor disabilities (including cerebral palsy) [10,11]. The presence of anxiety disorders and symptoms can affect an individual's quality of life [12], requiring the use of health services not only because of the disease itself, but also due to the variety of its causes, including cardiovascular diseases and increased mortality risk [13-16].

In the population without disabilities, physical exercise (PE) has been shown to be an accessible and inexpensive option to help reduce anxiety symptoms $[17,18]$. PE is characterized as a planned and systematic form of physical activity, consisting of a defined 
structure and repetition, with the purpose of maintaining or improving one or more components of physical fitness, namely, aerobic, neuromuscular capacity, balance, and flexibility [19]. The literature reinforces that PE presents itself as an effective method for the promotion of mental health [20-22].

Research has shown that in undiagnosed individuals, a single session of PE can cause a reduction in anxiety symptoms $[23,24]$. Moreover, individuals who practice PE have a lower risk of developing anxiety disorders compared to those who do not $[25,26]$. Furthermore, in diagnosed individuals, PE has also proven to be an effective method in the treatment of anxiety [18,27].

Although the benefits of PE are clear and evident for the general population, namely, in the reduction anxiety symptoms, the effects in the population with disabilities are still unclear and have not been evaluated, and researchers usually direct their interests to other variables [28-31]. It is important to understand if they are transversal to the population with disabilities in order to promote their quality of life, related to the conceptual model of Schalock et al. [32], being a construct divided into three dimensions: (i) Independence, (ii) social participation, and (iii) well-being.

This is the first systematic review a with meta-analysis aimed at identifying if PE programs can be a good method to reduce anxiety symptoms in individuals with disabilities, answering the following question: Can an exercise PE program reduce anxiety symptoms in individuals with disabilities?

\section{Methods}

\subsection{Eligibility Criteria}

This systematic review was constructed following the items of the PRISMA protocol [33] and the methodology described by Bento [34]. The protocol of this systematic review was registered in the International Prospective Register of Systematic Reviews (PROSPERO) International Prospective Register of Systematic Reviews, with registration number CRD42021256218 of 2021. The PICOS strategy [35,36] is defined as follows: (i) "P" (Patients) corresponds to participants with any type of disability, of any age, gender, ethnicity, or race; (ii) "I" (Intervention) corresponds to a PE program, implemented in the referred population, independently of the intervention time; (iii) " $\mathrm{C}$ " (Comparison) corresponds to the comparison before and after the intervention or between the control group and the intervention group; (iv) "O" (Outcome) corresponds to anxiety as the primary or secondary variable of focus; (v) "S" (Study Design) corresponds to intervention studies, randomized controlled trials (RCTs), or non-RCTs.

\subsection{Information Sources and Research Strategies}

The present study was carried out between May and June (Day 21) 2021, in English, by searching the databases, PubMed (all fields), Web of Science, Scopus, and SPORTDiscus (title, abstract, and keywords), considering studies from January 2001 to June 2021. The descriptors used were: "Cerebral palsy", "motor disability", "physical disability", "vision impairment", "visual impairment", "vision disability", "intellectual disability", "mental retardation", "intellectual disabilities", "hearing impairment", "hearing disability", "multiple disabilities", "physical activity", "exercise", "sport", "training", and "anxiety", with the Boolean operator "AND" or "OR", as shown in Table 1. 
Table 1. Research strategy.

\section{Research Number}

Descriptors

("brain palsy" OR "motor disability" OR "physical disability" OR "vision impairment" OR "visual impairment" OR "vision disability" OR "intellectual disability" OR "mental

OR "multiple disabilities") AND ("physical activity" OR "exercise" OR sport* OR "training") AND ("anxiety" OR "phobia" OR "panic")

\subsection{Inclusion Criteria}

For the selection of studies, the following inclusion criteria were considered: (i) Intervention studies, RCTs, and non-RCTs; (ii) intervention studies with PE; (iii) individuals with disabilities, of the most varied types; (iv) studies with individuals of any age group, gender, race, or ethnicity.

\subsection{Exclusion Criteria}

Likewise, the following exclusion criteria were considered: (i) Studies published before 2001; (ii) studies that were not published in English or Portuguese; (iii) studies that do not describe the intervention protocol; (iv) studies in which the intervention is not just PE.

\subsection{Data Extraction Process}

The research was carried out independently by two investigators, via the ENDNOTE X7 software (Clarivate, London, United Kingdom) and duplicated articles were eliminated. In the first phase, articles were excluded based on the reading of the titles and abstract. In the second phase, which consisted of a complete reading of the articles, those that did not meet the eligibility criteria were excluded, and the study sample consisted of four articles. The results at all phases were compared by the researchers (M.J. and R.A.). One of the researchers (M.J.) exported the relevant information from the articles and inserted them into Table 2 (authorship, year of publication, country, objectives, participants, type of study, assessment instruments, duration/frequency, exercises and intensities, and main results).

\subsection{Methodological Quality Assessment}

To assess the quality of each study, the Downs and Black scale was used [37]. This scale consists of 27 items, scored with "one value" or "zero" for various parts of each article. The quality of each study was assessed by two investigators (M.J. and R.A.), independently, and they were compared and discussed to reach a consensus. When a consensus was not possible, a third investigator was available to collaborate (R.F.). The scale was divided into several score ranges, corresponding to the following quality levels: Excellent (26-28); good (20-25); fair (15-19); and poor ( $\leq 14)$. However, as six questions (questions 8, 11, 12, 15, 16, and 27) were not applicable to all studies, they were removed. Once modified, the scale had a maximum of 20 points compared to the original.

\subsection{Statistical Analysis}

A meta-analysis was performed using Comprehensive Meta-analysis Version 3.0 statistical software (Biostact, Inc, Englewood, United States of America). The difference in means was calculated based on information on the pre- and post-intervention means, the number of participants, and the standard deviation, using the randomized effects model to measure the effect size, with a 95\% confidence interval (CI), magnitude effects, and level of statistical significance $(p<0.05)$. Heterogeneity was assessed using the chi-square, Cochran Q statistic, Higgin I squared $\left(\mathrm{I}^{2}\right)$, and Tau square tests $\left(\mathrm{T}^{2}\right)$. The homogeneity was verified by the asymmetry of the funnel-shaped scatter plot [38], and it was considered without publication bias when the graph had an inverted funnel [39]. 


\section{Results}

\subsection{Selection of Studies}

By searching the various databases, 330 studies were identified. In the first phase, after the elimination of duplicate articles and based on the titles and abstracts (eliminating articles that did not correspond to scientific publications, with an experimental methodology, with the implementation of a PE program, and evaluating its impact on anxiety symptoms), a sample of six studies with relevant potential for the study were identified for the next phase. Considering the eligibility criteria and the complete reading of the articles, a sample of four studies constituted the full analysis (two articles were excluded, in which the intervention was not with physical exercise or was not only with physical exercise).

Figure 1 represents a PRISMA flowchart of this systematic review.
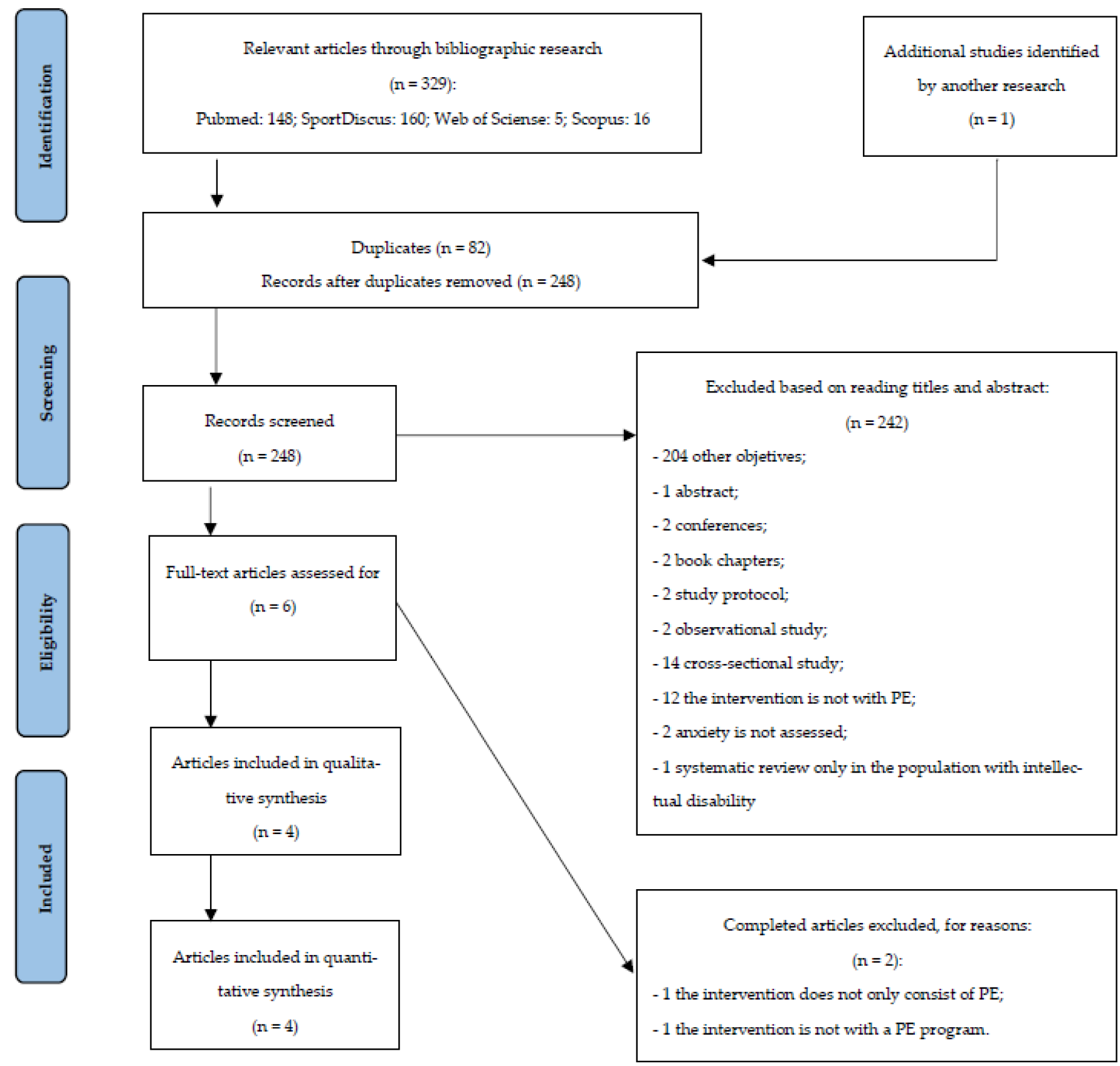

Figure 1. PRISMA flow diagram. 
Table 2. Characteristics of the four studies.

\begin{tabular}{|c|c|c|c|c|c|c|}
\hline Author, Year, Country & Aims & Participants & Type of Study & $\begin{array}{l}\text { Assessment Instru- } \\
\text { ments/Technique }\end{array}$ & Duration/Frequency & Exercises and Intensity \\
\hline $\begin{array}{l}\text { Barak et al. [40] } \\
\text { Israel }\end{array}$ & $\begin{array}{c}\text { Effects of Boccia on } \\
\text { psychosocial outcomes } \\
\text { in persons with severe } \\
\text { disabilities. }\end{array}$ & $\begin{array}{c}N=43 \\
\text { AA: } 45.60 \pm 10.95 \\
\text { y;multiple disabilities. }\end{array}$ & $\begin{array}{l}\text { (A) Competition boccia } \\
\text { group without } \\
\text { professional supervision } \\
(N=9) ;(B) \\
\text { professionally } \\
\text { supervised competition } \\
\text { bocce }(N=7) ;(C) \\
\text { recreational/leisure } \\
\text { bocce } \\
(N=14) ; \text { and }(D) \text { control } \\
(N=13) \text {. }\end{array}$ & $\begin{array}{l}\text { State-Trait Anxiety } \\
\text { Inventory; } \\
\text { State-Trait Anxiety } \\
\text { and Trait Anxiety } \\
\text { Scale (36-38)—-self- } \\
\text { reports. }\end{array}$ & $\begin{array}{c}16 \text { weeks; } \\
\text { Groups A and B trained } \\
3 \times \text { week; } \\
90 \mathrm{~min} / \text { session. }\end{array}$ & $\begin{array}{l}\text { Groups A and B: } \\
\text { Throwing balls to different } \\
\text { targets; technical and } \\
\text { tactical exercises; training } \\
\text { and competition games. } \\
\text { Groups A and B: Strength } \\
\text { training ( } 2 \times \text { week; } \\
60 \text { min/ session). } \\
\text { All groups participated in } \\
\text { a rehabilitation program. } \\
\text { Recreational participants } \\
\text { were included in the } \\
\text { training that emphasized } \\
\text { tactics }(2 \times \text { week), but not } \\
\text { in the games and not in } \\
\text { one specific training } \\
\text { schedule. }\end{array}$ \\
\hline
\end{tabular}


Table 2. Cont.

\begin{tabular}{|c|c|c|c|c|c|c|}
\hline Author, Year, Country & Aims & Participants & Type of Study & $\begin{array}{l}\text { Assessment Instru- } \\
\text { ments/Technique }\end{array}$ & Duration/Frequency & Exercises and Intensity \\
\hline $\begin{array}{l}\text { Hardoy et al. [42] } \\
\text { Italy }\end{array}$ & $\begin{array}{c}\text { Evaluating the efficacy } \\
\text { of an introductory mini } \\
\text { tennis program as a } \\
\text { therapeutic } \\
\text { aid in the psychosocial } \\
\text { rehabilitation of } \\
\text { participants affected by } \\
\text { mild-to-moderate ID. }\end{array}$ & $\begin{array}{c}N=24 ; \\
\text { AA: } 27.25 \pm 8.45 \mathrm{y} ; \\
\text { mild ID. }\end{array}$ & $\begin{array}{c}\text { Non-randomized } \\
\text { controlled experimental } \\
\text { study; } \\
\text { division of groups: } \\
\text { Training }(N=12) \text { and } \\
\text { control }(N=12) .\end{array}$ & $\begin{array}{c}\text { Assessment and } \\
\text { Information Rating } \\
\text { Profile—anxiety } \\
\text { subscale (Bouras, N. } \\
\text { and Drummond, C. } \\
\text { 1989) }\end{array}$ & $\begin{array}{c}24 \text { weeks; } \\
2 \times \text { week; } \\
180 \text { min/session. }\end{array}$ & $\begin{array}{c}\text { Phase-divided PE } \\
\text { program: } \\
\text { 1st phase: Exercises to } \\
\text { familiarize participants } \\
\text { with equipment (ball, } \\
\text { wooden paddles, and } \\
\text { racket); } \\
\text { 2nd phase: Development } \\
\text { of coordination skills } \\
\text { (oculo-manual, general } \\
\text { dynamics, and } \\
\text { temporal-spatial skills); } \\
\text { 3rd phase: Learning basic } \\
\text { tennis techniques. }\end{array}$ \\
\hline $\begin{array}{l}\text { Salehpoor et al. [43] } \\
\text { Iran }\end{array}$ & $\begin{array}{l}\text { Investigating the effect } \\
\text { of exercise on the anxiety } \\
\text { of adolescents with } \\
\text { intellectual disabilities. }\end{array}$ & $\begin{array}{l}N=30 \text { \% } \\
\text { A: } 15-21 \text { y; } \\
\text { mild ID. }\end{array}$ & $\begin{array}{l}\text { Quasi-experimental } \\
\text { study; } \\
\text { random groups: Training } \\
(N=15) \text { and control } \\
(N=15) .\end{array}$ & $\begin{array}{l}\text { Zung Self-Rating } \\
\text { Anxiety Scale (1997)_- } \\
\text { self-completion. }\end{array}$ & $\begin{array}{c}8 \text { weeks; } \\
3 \times \text { week; } \\
60 \mathrm{~min} / \text { session. }\end{array}$ & $\begin{array}{c}\text { Rhythmic aerobic exercises } \\
\text { were performed ( } 20 \mathrm{~min}) ; \\
\text { strength exercises } \\
\text { (20 min)-exercise with } \\
\text { dumbbells, ropes, and } \\
\text { balls. }\end{array}$ \\
\hline
\end{tabular}

A, age; AA, average age; ID, intellectual disability; Exer, exercise/s; min, minutes; $N$, participants; y, years; $\iota^{\natural}$, male; 9 , female. 


\subsection{Origin}

Two of the studies selected for full analysis were from the Asian continent $[40,43]$ and the two others were from the European continent [41,42], with Italy being the country that has published the most studies on this subject.

\subsection{Participants}

The study of Barak [40] recruited participants with multiple disabilities, with the other three studies having a sample of individuals with intellectual disabilities only. Using an experimental methodology in all studies, there was a sum of 124 participants, 53 of whom were part of the control group. The participants were in the age group of young people and adults.

\subsection{Assessment Instruments/Technique}

All authors used a scale to assess anxiety symptoms. The scales were applied through self-reports or self-completion, with the exception of the study of Hardoy [42], where the methodology used is not clear.

\subsection{PE Program}

The PE programs were different, with no trend regarding the training methodology used. However, we can observe Boccia modality training [40], mini tennis [42], and exercises with different dynamics [41], as well as combined strength and aerobic training [43].

The PE focused on a modality [40,42] consisting of a first phase with exercises to familiarize the participants with the equipment and, in a second phase, with the technical and tactical drills. Barak [40] prescribed another phase with competition games, while Hardoy [40] prescribed one phase with the development of coordination skills. The central phase of the Carraro and Gobbi's [41] and Salehpoor's [43] studies consisted of individual or paired movements using different equipment (balls, ropes, dumbbells, etc.), group cooperative situations, and adapted games.

The programs duration varied between 8 and 24 weeks. The weekly frequency varied between two and three times and the training sessions duration varied between 60 and $180 \mathrm{~min}$.

\subsection{Quality of Studies}

The methodological quality of the studies was assessed as poor to good. No studies were excluded due to low-quality scores. The study with the highest quality was Salehpoor's [43], while the study with the lowest quality assessment was developed by Barak [40]. The quality ratings are shown in Table 3.

\subsection{Results of the Interventions}

Table 3 shows the results of the PE programs on anxiety symptoms in individuals with disabilities. 
Table 3. Results of the interventions on anxiety symptoms.

\begin{tabular}{|c|c|c|c|c|c|c|c|c|c|c|}
\hline \multirow{4}{*}{$\begin{array}{l}\text { Barak et al. } \\
\quad[40]\end{array}$} & \multirow[b]{3}{*}{$\begin{array}{l}\text { Assessment instru- } \\
\text { ments/technique }\end{array}$} & \multicolumn{6}{|c|}{ Intervention Group } & \multicolumn{2}{|c|}{ Control Group } & \multirow{2}{*}{$\begin{array}{c}\text { Methodologica } \\
\text { Quality }\end{array}$} \\
\hline & & \multicolumn{3}{|c|}{ Pre-Test } & \multicolumn{3}{|c|}{ Post-Test } & \multirow{3}{*}{$\begin{array}{c}\text { Pre-Test } \\
25.76 \pm 10.34\end{array}$} & \multirow{3}{*}{$\begin{array}{c}\text { Post-Test } \\
25.25 \pm 10.90\end{array}$} & \\
\hline & & $\begin{array}{c}\text { Intervention } \\
\mathrm{A}\end{array}$ & $\begin{array}{c}\text { Intervention } \\
\text { B }\end{array}$ & $\begin{array}{c}\text { Intervention } \\
\mathrm{C}\end{array}$ & $\begin{array}{c}\text { Intervention } \\
\mathrm{A}\end{array}$ & $\begin{array}{c}\text { Intervention } \\
\text { B }\end{array}$ & $\begin{array}{c}\text { Intervention } \\
\text { C }\end{array}$ & & & \multirow{3}{*}{ Poor } \\
\hline & Anxiety State & $23.55 \pm 5.38$ & $27.00 \pm 10.27$ & $30.07 \pm 4.61$ & $20.55 \pm 7.69$ & $21.28 \pm 5.82$ & $30.07 \pm 7.93$ & & & \\
\hline & Trait Anxiety & $24.44 \pm 8.95$ & $26.00 \pm 10.68$ & $30.50 \pm 5.01$ & & $\mathrm{NE}$ & & $25.38 \pm 10.35$ & $\mathrm{NE}$ & \\
\hline $\begin{array}{l}\text { Carraro and } \\
\text { Gobbi [41] }\end{array}$ & Trait Anxiety & & $59.9 \pm 2.9$ & & & $38.1 \pm 2.5$ & & $59.8 \pm 4.3$ & $57.2 \pm 4.3$ & Good \\
\hline $\begin{array}{l}\text { Hardoy et al. } \\
{[42]}\end{array}$ & $\begin{array}{l}\text { Assessment and } \\
\text { Information Rating } \\
\text { Profile Anxiety } \\
\text { Subscale }\end{array}$ & & $3.2 \pm 1.8$ & & & $2.3 \pm 1.3$ & & $2.8 \pm 2.3$ & $2.8 \pm 2.3$ & Fair \\
\hline $\begin{array}{l}\text { Salehpoor } \\
\text { et al. [43] }\end{array}$ & $\begin{array}{l}\text { Zung's Anxiety } \\
\text { Scale (1997) }\end{array}$ & & $43.15 \pm 0.96$ & & & $36.60 \pm 1.10$ & & $43.75 \pm 1.19$ & $45.91 \pm 1.46$ & Good \\
\hline
\end{tabular}


Taking into account the objectives of this systematic review, we found that all studies that assessed anxiety had a decrease in its (anxiety) levels, through the implementation of PE programs.

Figure 2 presents the meta-analysis results.

Study name

Study name
Barak et al., (2016)
Barak et al., (2016)b
Barak et al., (2016)c
Carraro \& Gobbi (2012)
Carraro \& Gobbi (2012)b
Hardoy et al., (2011)
Salehpoor et al., (2015)

\begin{tabular}{|c|c|c|c|c|c|c|}
\hline \multirow[b]{2}{*}{$\begin{array}{l}\text { Std diff } \\
\text { in means }\end{array}$} & \multicolumn{5}{|c|}{ Statistics for each study } & \multirow[b]{2}{*}{ p-Value } \\
\hline & $\begin{array}{l}\text { Standard } \\
\text { error }\end{array}$ & Variance & $\begin{array}{c}\text { Lower } \\
\text { limit }\end{array}$ & $\begin{array}{l}\text { Upper } \\
\text { limit }\end{array}$ & Z-Value & \\
\hline 0,343 & 0,437 & 0,191 & $-0,513$ & 1,198 & 0,785 & 0,433 \\
\hline 0,652 & 0,480 & 0,230 & $-0,289$ & 1,593 & 1,358 & 0,174 \\
\hline 0,072 & 0,385 & 0,148 & $-0,683$ & 0,827 & 0,188 & 0,851 \\
\hline 6,933 & 1,019 & 1,038 & 4,935 & 8,930 & 6,803 & 0,000 \\
\hline 4,775 & 0,755 & 0,571 & 3,295 & 6,256 & 6,322 & 0,000 \\
\hline 0,579 & 0,417 & 0,174 & $-0,237$ & 1,396 & 1,390 & 0,165 \\
\hline 1,372 & 0,406 & 0,165 & 0,576 & 2,167 & 3,380 & 0,001 \\
\hline & & & & & & \\
\hline
\end{tabular}

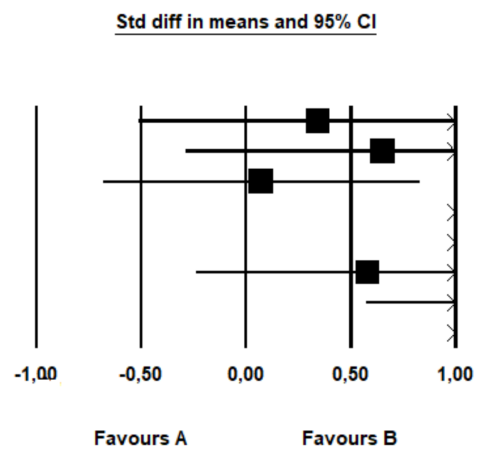

Figure 2. Summary of the descriptive and inferential statistics of the results of each study and the overall effect size of the effect on the anxiety symptoms in individuals with disabilities.

The sum of the effects was 1.875, which means that individuals from the intervention group presented approximately 1.9 times more probability to report improvements when compared to the control group. The range of confidence for the difference in means was 0.632 (lower limit) to 3.117 (upper limit), which means that the raw mean difference, in the universe of studies, may fall somewhere in this range. On the contrary, this range did not include a zero difference, which means that the true difference of means (true difference in means) is a value other than zero. The $\mathrm{Z}$ values (Z-values) obtained to test the null hypothesis, according to which the difference of means was zero, demonstrated by $\mathrm{Z}=2.957$, with a corresponding $p$-value of 0.003 . Therefore, the null hypothesis can be rejected, according to which $\mathrm{PE}$ does not affect the anxiety of individuals with disabilities. The obtained value of $Q$ was 69,291 with six degrees of freedom and a $p$-value $<0.01$. Thus, we can reject the null hypothesis that the true effect size is the same in all studies. On the contrary, the true effect size varied from study to study. In this meta-analysis, the $I^{2}$ value obtained was 91,341 , which means approximately $91 \%$ of the variance in the observed effects reflects the variance of true effects. $T^{2}$ corresponds to the variance of the true magnitude of the effects (true effect sizes) among that studies that, in this study, presented a value of 2.482. The value of $\mathrm{T}$, on the contrary, refers to the standard deviation of the true magnitude of the effects, and in the present meta-analysis equaled 1.576.

In addition, the Egger test was carried out (Figure 3), which proposes to test the null hypothesis according to which the intercept is equal to zero in the population. In Figure 2, the intercept is $1,077,080$, the $95 \%$ confidence interval is $(615,969,1,538,192)$, with $t=6.00445$ and $\mathrm{gl}=5$. The recommended $p$-value (two-tailed) is 0.00184 . Thus, there is statistical evidence of the existence of publication bias. This reflects those smaller studies (which appear toward the lower) are more likely to be published if they show effects greater than the average, making them more likely to meet the criterion of statistical significance. 


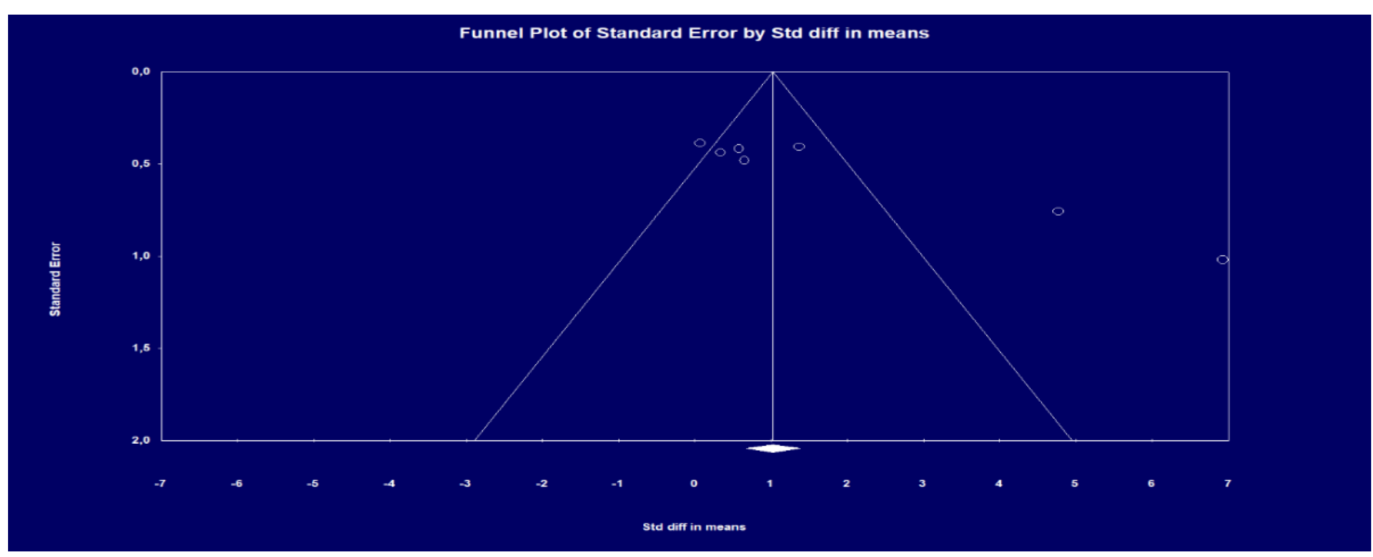

Figure 3. Funnel scatter plot to check publication bias.

\section{Discussion}

This systematic review with a meta-analysis aimed to identify if PE programs can be a good method to reduce anxiety symptoms in the population with disabilities.

Intervention with a combination of factors (physical involvement, experience of skills improvement, and social relationships) [37,39] could have an anxiety-reducing effect. On the contrary, training with a modality not only promotes physical fitness and abilities such as accuracy, but also strategic planning, mental toughness, comprehensive learning processes, and social exchange [36,39]. Although the methodologies were different, socialization proved to be an important element for the success of PE programs.

It was observed that all interventions had positive effects at the level of the studied variables. In addition to the physical benefits, PE is an affordable and inexpensive option to reduce anxiety symptoms in the general population $[17,18]$ and, as evidenced by our systematic review with a meta-analysis, in the population with disabilities.

Institutions/organizations/clubs that provide support to the target population should take into account the results of this study, namely, at the moment of planning strategies and interventions for individuals with disabilities. In addition to promoting physical fitness, PE reduces anxiety symptoms, being an asset to improving quality of life.

The present systematic review with a meta-analysis found only four studies that met the eligibility criteria, which may have limited the results and conclusions of this study. Therefore, the results should be considered with caution. At the same time, three of the four studies included only included individuals with intellectual disabilities. This fact is an indicator of the need to continue to implement PE programs among the population with disabilities, in its various types, and to understand the effect that these programs can have, not only in terms of physical health, but also mental health. Future studies should also evaluate the impact of PE on reducing anxiety symptoms in different gender or age groups. Moreover, the mechanisms involved in reducing anxiety symptoms must continue to be investigated in order to better prescribe a PE program for individuals with disabilities.

\section{Conclusions}

Taking into account the results shown in this systematic review with a meta-analysis, $\mathrm{PE}$ is a good method for reducing anxiety symptoms in individuals with disabilities, as well as a good method to promote their quality of life.

Author Contributions: Conceptualization, M.J., R.F., R.M., and R.A.; methodology, M.J., R.F., and R.A.; software, M.J.; validation, M.J., R.F., and R.A.; formal analysis, M.J., R.F., R.M., and R.A.; investigation, M.J. and R.A.; resources, M.J. and R.A.; data curation, M.J.; writing - original draft preparation, M.J.; writing-review and editing, M.J., R.F., R.M., and R.A.; visualization, M.J., R.F., R.M., and R.A.; supervision, M.J., R.F., R.M., and R.A.; project administration, M.J. All authors have read and agreed to the published version of the manuscript. 
Funding: This research was supported by the Portuguese Foundation for Science and Technology, I.P., grant/award number UIDB/04748/2020.

Data Availability Statement: Additional data are available upon request to the corresponding author.

Conflicts of Interest: The authors have no conflict of interest to disclose.

\section{References}

1. American Psychiatric Association. Diagnostic and Statistical Manual of Mental Disorders (DSM-5); American Psychiatric Association: Washington DC, USA, 2013.

2. Simpson, H.; Neria, Y.; Lewis-Fernández, R.; Schneier, F. Anxiety Disorders: Theory, Research and Clinical Perspectives; Cambridge University Press: New York, NY, USA, 2010.

3. Kessler, R.C.; Aguilar-Gaxiola, S.; Alonso, J.; Chatterji, S.; Lee, S.; Ormel, J.; Ustün, T.B.; Wang, P.S. The global burden of mental disorders: An update from the WHO World Mental Health (WMH) surveys. Epidemiol. Psichiatr. Soc. 2009, 18, 23-33. [CrossRef]

4. Whiteford, H.A.; Ferrari, A.J.; Degenhardt, L.; Feigin, V.; Vos, T. The Global Burden of Mental, Neurological and Substance Use Disorders: An Analysis from the Global Burden of Disease Study 2010. PLoS ONE 2015, 10, e0116820. [CrossRef] [PubMed]

5. Wittchen, H.U.; Jacobi, F.; Rehm, J.; Gustavsson, A.; Svensson, M.; Jönsson, B.; Olesen, J.; Allgulander, C.; Alonso, J.; Faravelli, C.; et al. The size and burden of mental disorders and other disorders of the brain in Europe 2010. Eur. Neuropsychopharmacol. 2011, 21, 655-679. [CrossRef] [PubMed]

6. Remes, O.; Brayne, C.; Vander, L.R.; Lafortune, L. A systematic review of reviews on the prevalence of anxiety disorders in adult populations. Brain Behav. 2016, 6, e00497. [CrossRef] [PubMed]

7. Maïano, C.; Coutu, S.; Tracey, D.; Bouchard, S.; Lepage, G.; Morin, A.J.S.; Moullec, G. Prevalence of anxiety and depressive disorders among youth with intellectual disabilities: A systematic review and meta-analysis. J. Affect. Disord 2018, 236, 230-242. [CrossRef]

8. Binder, K.W.; Wrzesińska, M.A.; Kocur, J. Anxiety in persons with visual impairment. Psychiatr. Pol. 2020, 54, 279-288. [CrossRef] [PubMed]

9. Shoham, N.; Lewis, G.; Favarato, G.; Cooper, C. Prevalence of anxiety disorders and symptoms in people with hearing impairment: A systematic review. Soc. Psychiatry Psychiatr. Epidemiol. 2019, 54, 649-660. [CrossRef] [PubMed]

10. Jones, K.H.; Jones, P.A.; Middleton, R.M.; Ford, D.V.; Tuite-Dalton, K.; Lockhart-Jones, H.; Peng, J.; Lyons, R.A.; John, A.; Noble, J.G. Physical Disability, Anxiety and Depression in People with MS: An Internet-Based Survey via the UK MS Register. PLoS ONE 2014, 9, e104604. [CrossRef] [PubMed]

11. Smith, K.J.; Peterson, M.D.; O'Connell, N.E.; Victor, C.; Liverani, S.; Anokye, N.; Ryan, J.M. Risk of Depression and Anxiety in Adults With Cerebral Palsy. JAMA Neurol. 2019, 76, 294-300. [CrossRef]

12. Stein, M.B.; Roy-Byrne, P.P.; Craske, M.G.; Bystritsky, A.; Sullivan, G.; Pyne, J.M.; Katon, W.; Sherbourne, C.D. Functional impact and health utility of anxiety disorders in primary care outpatients. Med. Care 2005, 43, 1164-1170. [CrossRef]

13. Haller, H.; Cramer, H.; Lauche, R.; Gass, F.; Dobos, G.J. The prevalence and burden of subthreshold generalized anxiety disorder: A systematic review. BMC Psychiatry 2014, 14, 128. [CrossRef]

14. Moser, D.K.; McKinley, S.; Riegel, B.; Doering, L.V.; Meischke, H.; Pelter, M.; Patricia, D.; Kathleen, D. Relationship of persistent symptoms of anxiety to morbidity and mortality outcomes in patients with coronary heart disease. Psychosom. Med. 2011, 73, 803-809. [CrossRef] [PubMed]

15. Roest, A.M.; Martens, E.J.; de Jonge, P.; Denollet, J. Anxiety and Risk of Incident Coronary Heart Disease: A Meta-Analysis. JACC 2010, 56, 38-46. [CrossRef] [PubMed]

16. Tolmunen, T.; Lehto, S.M.; Julkunen, J.; Hintikka, J.; Kauhanen, J. Trait anxiety and somatic concerns associate with increased mortality risk: A 23-year follow-up in aging men. Ann. Epidemiol. 2014, 24, 463-468. [CrossRef] [PubMed]

17. Aylett, E.; Small, N.; Bower, P. Exercise in the treatment of clinical anxiety in general practice - A systematic review and meta-analysis. BMC Health Serv. Res. 2018, 18, 559. [CrossRef]

18. Stonerock, G.L.; Hoffman, B.M.; Smith, P.J.; Blumenthal, J.A. Exercise as Treatment for Anxiety: Systematic Review and Analysis. Ann. Behav Med. 2015, 49, 542-556. [CrossRef] [PubMed]

19. Caspersen, C.J.; Powell, K.E.; Christenson, G.M. Physical activity, exercise, and physical fitness: Definitions and distinctions for health-related research. Public Health Rep. 1985, 100, 126-131. [PubMed]

20. Andermo, S.; Hallgren, M.; Nguyen, T.T.D.; Jonsson, S.; Petersen, S.; Friberg, M.; Romqvist, A.; Stubbs, B.; Elinder, L.S. Schoolrelated physical activity interventions and mental health among children: A systematic review and meta-analysis. Sports Med. Open 2020, 6, 25. [CrossRef] [PubMed]

21. Rodriguez-Ayllon, M.; Cadenas-Sánchez, C.; Estévez-López, F.; Muñoz, N.E.; Mora-Gonzalez, J.; Migueles, J.H.; García, P.M.; Henriksson, H.; Molina, A.M.; Vizcaíno, V.M.; et al. Role of Physical Activity and Sedentary Behavior in the Mental Health of Preschoolers, Children and Adolescents: A Systematic Review and Meta-Analysis. Sports Med. 2019, 49, 1383-1410. [CrossRef] [PubMed]

22. Rosenbaum, S.; Tiedemann, A.; Sherrington, C.; Curtis, J.; Ward, P.B. Physical activity interventions for people with mental illness: A systematic review and meta-analysis. J. Clin. Psychiatry 2014, 75, 964-974. [CrossRef] [PubMed] 
23. Esquivel, G.; Díaz-Galvis, J.; Schruers, K.; Berlanga, C.; Lara-Muñoz, C.; Griez, E. Acute exercise reduces the effects of a 35\% CO2 challenge in patients with panic disorder. J. Affect. Disord 2008, 107, 217-220. [CrossRef] [PubMed]

24. Strickland, J.C.; Smith, M.A. The anxiolytic effects of resistance exercise. Front. Psychol. 2014, 5, 753. [CrossRef] [PubMed]

25. De Moor, M.H.M.; Beem, A.L.; Stubbe, J.H.; Boomsma, D.I.; De Geus, E.J.C. Regular exercise, anxiety, depression and personality: A population-based study. Prev. Med. 2006, 42, 273-279. [CrossRef] [PubMed]

26. Goodwin, R.D. Association between physical activity and mental disorders among adults in the United States. Prev. Med. 2003, 36, 698-703. [CrossRef]

27. Jayakody, K.; Gunadasa, S.; Hosker, C. Exercise for anxiety disorders: Systematic review. Br. J. Sports Med. 2014, 48, 187-196. [CrossRef] [PubMed]

28. Bartlo, P.; Klein, P.J. Physical activity benefits and needs in adults with intellectual disabilities: Systematic review of the literature. Am. J. Intellect Dev. Disabil 2011, 116, 220-232. [CrossRef] [PubMed]

29. Kapsal, N.J.; Dicke, T.; Morin, A.J.S.; Vasconcellos, D.; Maïano, C.; Lee, J.; Lonsdale, C. Effects of Physical Activity on the Physical and Psychosocial Health of Youth With Intellectual Disabilities: A Systematic Review and Meta-Analysis. J. Phys. Act. Health 2019, 16, 1187-1195. [CrossRef] [PubMed]

30. Priego Quesada, J.I.; Lucas-Cuevas, A.; Belloch, S.; Perez-Soriano, P. Effects of exercise in people with cerebral palsy. A review. J. Phys. Educ. Sport 2014, 14, 36-41.

31. Sweeting, J.; Merom, D.; Astuti, P.A.S.; Antoun, M.; Edwards, K.; Ding, D. Physical activity interventions for adults who are visually impaired: A systematic review and meta-analysis. BMJ Open 2020, 10, e034036. [CrossRef]

32. Schalock, R.; Verdugo, M. Handbook on Quality of Life for Human Service Practitioners; American Association on Mental Retardation: Washington DC, USA, 2002.

33. Moher, D.; Shamseer, L.; Clarke, M.; Ghersi, D.; Liberati, A.; Petticrew, M.; Shekelle, P.; Stewart, L.A.; Group, P.P. Preferred reporting items for systematic review and meta-analysis protocols (PRISMA-P) 2015 statement. Syst. Rev. 2015, 4, 1. [CrossRef]

34. Bento, T. Revisões sistemáticas em desporto e saúde: Orientações para o planeamento, elaboração, redação e avaliação. Motricidade 2014, 10, 107-123. [CrossRef]

35. Methley, A.M.; Campbell, S.; Chew-Graham, C.; McNally, R.; Cheraghi-Sohi, S. PICO, PICOS and SPIDER: A comparison study of specificity and sensitivity in three search tools for qualitative systematic reviews. BMC Health Serv. Res. 2014, 14, 579. [CrossRef] [PubMed]

36. Nang, C.; Piano, B.; Lewis, A.; Lycett, K.; Woodhouse, M. Using The PICOS Model To Design And Conduct A Systematic Search: A Speech Pathology Case Study; Edith Cowan University: Perth, Australia, 2015.

37. Downs, S.H.; Black, N. The feasibility of creating a checklist for the assessment of the methodological quality both of randomised and non-randomised studies of health care interventions. J. Epidemiol. Community Health 1998, 52, 377-384. [CrossRef] [PubMed]

38. Egger, M.; Smith, G.D.; Schneider, M.; Minder, C. Bias in meta-analysis detected by a simple, graphical test. BMJ 1997, 315, 629-634. [CrossRef] [PubMed]

39. Higgins, J.P.; Altman, D.G. Assessing Risk of Bias in Included Studies. In Cochrane Handbook for Systematic Reviews of Interventions; Higgins, J.P.T., Altman, D.G., Sterne, J.A.C., Eds.; John Wiley \& Sons: Chichester, UK, 2019.

40. Barak, S.; Mendoza-Laiz, N.; Fuentes, M.T.G.; Rubiera, M.; Huyzler, Y. Psychosocial effects of competitive Boccia program in persons with severe chronic disability. J. Rehabil Res. Dev. 2016, 53, 973-988. [CrossRef] [PubMed]

41. Carraro, A.; Gobbi, E. Effects of an exercise programme on anxiety in adults with intellectual disabilities. Res. Dev. Disabil 2012, 33, 1221-1226. [CrossRef] [PubMed]

42. Hardoy, M.C.; Seruis, M.L.; Floris, F.; Sancassiani, F.; Moro, M.F.; Mellino, G.; Lecca, M.E.; Adamo, S.; Carta, M.G. Benefits of Exercise with Mini Tennis in Intellectual Disabilities: Effects on Body Image and Psychopathology. Clin. Pract. Epidemiol. Ment. Health 2011, 7, 157-160. [CrossRef] [PubMed]

43. Salehpoor, M.; Salesi, M.; Hemati Alamdarloo, G. The Effect of Exercise on Anxiety of Adolescents with Intellectual Disability. Phys. Treat. Specif. Phys. Ther. J. 2015, 5, 25-32. 